\title{
Narrativas sobre vacinação em tempos de fake news: uma análise de conteúdo em redes sociais
}

\section{Narratives about vaccination in the age of fake news: a content analysis on social networks}

\author{
Luisa Massarania \\ (D) https://orcid.org/0000-0002-5710-7242 \\ E-mail: luisa.massarani7ळgmail.com \\ Igor Waltzc \\ (D) https://orcid.org/0000-0003-1903-6153 \\ E-mail: igor.waltzœgmail.com \\ Tatiane Leal ${ }^{\mathrm{a}}$ \\ (D) https://orcid.org/0000-0002-0410-809X \\ E-mail: tatianeclcœgmail.com \\ Michelle Modesto ${ }^{b}$ \\ (iD) https://orcid.org/0000-0002-8767-7190 \\ E-mail: shellymodestoðgmail.com \\ aFundação Oswaldo Cruz. Instituto Nacional de Comunicação \\ Pública da Ciência e Tecnologia (INCT-CPCT). Rio de Janeiro, \\ RJ, Brasil. \\ buniversidade Federal Fluminense. Instituto de Arte e \\ Comunicação Social. Niterói, RJ, Brasil. \\ 'Fundação Oswaldo Cruz. Instituto Oswaldo Cruz (IOC/Fiocruz), \\ e Instituto Nacional de Comunicação Pública da Ciência e \\ Tecnologia (INCT-CPCT). Rio de Janeiro, RJ, Brasil.
}

\section{Correspondência}

Luisa Massarani

Fundação Oswaldo Cruz. Av. Brasil, 4.036, Prédio da Expansão, sala 414. Rio de Janeiro, RJ, Brasil. CEP 21040-360.

\section{Resumo}

A vacina é um recurso fundamental para a promoção da saúde pública. Entretanto, uma crescente hesitação vacinal tem sido associada à desinformação em redes sociais. Nesse contexto, é importante investigar que informações sobre a vacina têm sido mais consumidas nesses espaços. Neste artigo, analisamos os cem links contendo a palavra "vacina" que geraram mais engajamento nas redes sociais entre 22 de maio de 2018 e 21 de maio de 2019, utilizando uma versão adaptada do protocolo de análise de conteúdo desenvolvido pela Rede Ibero-Americana de Capacitação e Monitoramento em Jornalismo Científico. 0 objetivo é investigar os discursos, enquadramentos e emissores que mais mobilizaram o debate público on-line. Analisando as características gerais, os temas, as narrativas, o tratamento e os atores desses conteúdos, concluímos que, apesar de, em sua maioria, veicularem uma visão positiva em relação às vacinas e trazerem dados verificáveis, existem lacunas na capacidade de sanar possíveis dúvidas quanto às vacinas, bem como em esclarecer de que forma a vacinação deve ser inserida no cotidiano de cuidados com a saúde das pessoas.

Palavras-chave: Vacina; Divulgação Científica; Redes Sociais. 


\section{Introdução}

The vaccine is a key resource for the promotion of public health. However, an increasing vaccine hesitancy has been associated with disinformation on social networks. In this context, it is important to investigate which contents about vaccines have been most consumed in these spaces. In our article, we analyze one hundred links containing the word "vaccine" with more engagement in social networks between May 22, 2018, and May 21, 2019, using an adapted version of the content analysis protocol developed by the Ibero-American Network for Monitoring and Training in Science Journalism. Our aim is to investigate the speeches, frameworks and broadcasters that most mobilized the public debate in these digital platforms. By analyzing the general characteristics, the themes, the narratives, the treatment and the actors mobilized by these contents, we conclude that, although they mostly convey a positive view about vaccines and bring verifiable data, there are gaps in the capacity to remedy possible doubts concerning vaccines and explain how vaccination should be inserted in people's daily health care.

Keywords: Vaccine; Science Communication; Social Networks.
Nos últimos anos, a internet ganhou proeminência como esfera de mediação da vida social. Redes sociais e aplicativos de mensagens, como Facebook, Twitter e WhatsApp, têm reconfigurado os modos de sociabilidade e o consumo de informação, constituindo-se como espaços privilegiados de (re)circulação e apropriação de conteúdos sobre ciência e tecnologia ( $C \& T)$ e saúde. Assim, ao mesmo tempo em que se tornam um importante meio para a popularização da ciência, facilitando a intercomunicação entre pacientes, médicos e pesquisadores, e potencializando o alcance de campanhas de promoção da saúde, as redes sociais também abrem uma oportunidade significativa para a disseminação de informações falsas e distorcidas (Moorhead et al., 2013).

As redes digitais se tornaram terreno fértil para a escalada de produção e circulação de fake news, mensagens totalmente falsas ou contendo elementos propositalmente enganosos, em seu conteúdo ou contexto (Bakir; McStay, 2017). Essas construções discursivas simulam elementos da linguagem e do formato das notícias "reais", o que dificulta a apreciação crítica por parte do público (Tandoc Junior; Lim; Ling, 2017). Contudo, é preciso considerar nuances que diferenciam as informações falsas intencionalmente construídas e compartilhadas de outros tipos de mensagens, como aquelas geradas a partir de erros de interpretação, imprecisões na apuração jornalística, opiniões, crenças pessoais, sátiras e paródias. Portanto, por maior que seja o desafio de estabelecer fronteiras quanto à ideia de "desinformação", tomamos a proposição de Wardle e Derakhshan (2017) como base, para quem o conceito diz respeito a informações deliberadamente falsas ou distorcidas, com o intuito de prejudicar pessoas, grupos sociais ou organizações.

No campo da $C \& T$, a dispersão de informações falsas aliada à falta de compreensão sobre a ciência é hoje um importante desafio à divulgação científica (Scheufele; Krause, 2019). As informações falsas com aparência científica se propagam facilmente na rede, pois apelam a questões que afetam o cotidiano dos usuários, que não conseguem avaliar facilmente o conteúdo ou identificar em quais fontes confiar 
(Molina-Cañabate; Magallón-Rosa, 2020). Além disso, a desinformação científica tende a mobilizar usuários, recorrendo a emoções como medo, aversão ou surpresa (Taddicken; Wolff, 2020).

Especificamente no campo da saúde, as redes sociais têm contribuído para proliferar a desinformação acerca de um recurso fundamental para a promoção da saúde pública: a vacinação. A vacinação em massa de populações traz como benefícios a erradicação, a prevenção e o controle de doenças, assim como a queda de mortalidade e de morbidade e a diminuição de custos dos sistemas de saúde com tratamentos (Kennedy, 2020).

No Brasil, a criação do Programa Nacional de Imunizações (PNI), em 1973, representou um marco na sistematização e na ampliação da vacinação como um recurso de saúde pública. Ao longo de sua existência, o programa unificou o calendário vacinal; padronizou os processos técnicos; combinou a vacinação de rotina com estratégias de campanha; investiu na produção nacional; ampliou a cobertura demográfica, etária e de vacinas; e promoveu políticas avaliativas, de vigilância epidemiológica e de educação em saúde (Silva Junior, 2013; Temporão, 2003).

Por essa atuação, o PNI é reconhecido internacionalmente como um programa de saúde pública de referência. Fortalecido ainda mais após a criação do Sistema Único de Saúde, o PNI teve um papel fundamental para construir uma consciência da vacinação como um direito a ser disponível universal e equitativamente a toda a população (Silva Junior, 2013; Temporão, 2003). Atualmente, o sistema público responde a 90\% das demandas por doses de vacinas humanas no país (Gadelha et al., 2020).

Entretanto, a cobertura vacinal no Brasil e em diversos países tem sido ameaçada pelo fenômeno da hesitação vacinal, definida como um conjunto de atitudes que vão desde a relutância até a recusa da vacina, apesar da disponibilidade dos serviços de vacinação. Trata-se, portanto, de um espectro que comporta diferentes níveis de incerteza, em cujo extremo se localiza o movimento antivacina, que se opõe à vacinação em qualquer circunstância. As causas da hesitação vacinal variam de acordo com a localidade, o tempo e as diferentes vacinas; logo, é importante analisar o contexto em que essas percepções são formadas e compartilhadas (OMS, 2014).
No contemporâneo, o papel da desinformação na hesitação vacinal tem sido considerado como um aspecto fundamental nesse processo em diversos países. As atitudes antivacina e a hesitação vacinal decorrem de vários fatores, incluindo a circulação de fake news (ECDC, 2017). Estudos em mídias sociais demonstram que discursos antivacinas tendem a contestar a segurança e a apelar à autoridade paterna contra ingerências das instituições políticas e de saúde (Krishna, 2018), e que indivíduos com atitude antivacinação tendem a desprezar informações corretas e a valorizar informações que reforcem suas convicções (Cuesta-Cambra; Martínez-Martínez; NiñoGonzález, 2019). Assim, as redes antivacinação podem ser de difícil contenção pelas intervenções sanitárias (Vasconcellos-Silva; Castiel; Griep, 2015).

No contexto brasileiro, um estudo realizado pela plataforma digital para mobilizações sociais Avaaz e pela Sociedade Brasileira de Imunizações (SBIm) revelou que a desinformação acerca das vacinas atingiu níveis alarmantes no país: ao serem apresentados a uma lista de mitos sobre vacinação, $67 \%$ dos entrevistados identificaram como verdadeira pelo menos uma declaração factualmente imprecisa. Entre os $13 \%$ que afirmaram não terem se vacinado ou não terem vacinado uma criança sob seus cuidados, mais da metade (57\%) se justificou a partir de crenças consideradas incorretas pela SBIm e/ou pela Organização Mundial da Saúde, como a falta de necessidade da vacinação ou o risco de efeitos colaterais nocivos (Avaaz; SBIm, 2019).

O papel das redes sociais e dos aplicativos de mensagens nesse cenário é primordial: para $48 \%$ dos entrevistados, eles são a principal fonte de informação sobre vacinas, atrás apenas da “mídia tradicional” (rádio, televisão, jornais e sites ligados à grande imprensa), com preferência de $68 \%$. Esses meios on-line, no entanto, destacam-se como fatores de risco na propensão à desinformação: dentre as pessoas que acreditaram em informações falsas, $73 \%$ utilizam redes sociais e aplicativos de mensagens como fontes.

Esse quadro encontra correspondências com dados de estudos internacionais. Em uma pesquisa de 2018 com entrevistados em 140 países, o Wellcome Global Monitor revelou que pessoas que recentemente buscaram informações sobre 
ciência $(74 \%)$ ou medicina e saúde $(75 \%)$ foram menos propensas a concordar com a segurança das vacinas do que aquelas que não procuraram esse tipo de informação ( $81 \%$ e $82 \%$, respectivamente) (Wellcome, 2019). Portanto, o problema parece apontar não para uma falta de informações, mas para a qualidade do conteúdo consumido.

Desse modo, torna-se relevante investigar o estado atual do debate público sobre vacinas nas redes sociais e os principais discursos que o mobilizam. É de grande importância ampliar o entendimento sobre a qualidade das informações que circulam sobre as vacinas, especialmente em um momento em que o Brasil registra quedas de até $27 \%$ na cobertura vacinal entre 2014 e 2019 (Cancian, 2020). Neste artigo, buscamos avaliar as informações acerca das vacinas que circulam nas redes sociais no Brasil, com o objetivo de compreender quais publicações sobre a vacinação têm gerado engajamento do público, e quais são os principais temas, tratamentos, enquadramentos e visões impulsionados em torno dessa questão, de forma a contribuir para a compreensão das relações entre redes sociais, desinformação e saúde pública.

\section{Metodologia}

Com o intuito de analisar os debates públicos a respeito do tema das vacinas, analisamos as publicações com mais interações nas plataformas digitais. Selecionamos um corpus formado pelas 100 publicações com a palavra-chave "vacina", com o maior número de compartilhamentos, curtidas e comentários em redes sociais ao longo de um ano. A coleta foi feita por meio do BuzzSumo, ${ }^{1}$ ferramenta que avalia a performance de conteúdos nas plataformas Facebook, Twitter, Pinterest e Reddit. Os resultados foram filtrados pelos seguintes critérios: (1) data de publicação entre 22 de maio de 2018 e 21 de maio de 2019² (12 meses); (2) apenas publicações em língua portuguesa; e (3) somente publicações contendo links, visando permitir sua análise.
Adotamos os dados de interação coletados pelo BuzzSumo - a mobilização dos públicos por meio dos protocolos interativos, como "comentar", "curtir" e "compartilhar" - como um parâmetro verificável de engajamento em torno das vacinas. Por mais que esses protocolos condicionem a ação dos interagentes, e que os critérios de distribuição e consumo de informações em redes sociais estejam sujeitos a uma ação algorítmica não completamente esclarecida, é possível depreender alguns achados sobre os contornos atuais do debate público nesse ambiente digital.

Dessa maneira, chegamos a uma lista com 100 endereços eletrônicos. Algumas páginas desativadas foram recuperadas pela ferramenta Wayback Machine, ${ }^{3}$ que armazena cópias dos sites nas datas em que são visitados. Apesar dos esforços para a recuperação, nossa amostra final acabou reduzida a 87 links. Com o corpus organizado, aplicamos o protocolo analítico desenvolvido pela Rede IberoAmericana de Capacitação e Monitoramento em Jornalismo Científico (Massarani; Ramalho, 2012), que permite traçar panoramas da cobertura de temas, como pesquisas e divulgação científicas, instituições, profissionais e políticas de C\&T. Neste trabalho, o protocolo foi adaptado a um corpus heterogêneo, composto não apenas por notícias científicas, mas também conteúdos ficcionais, artigos de opinião e fake news. Além disso, o protocolo se destina a analisar notícias sobre temas gerais da ciência, enquanto nossa análise se destinou a especificamente publicações sobre vacinas.

Consideramos importante examinar todos os resultados, inclusive os conteúdos ficcionais e textos em que a vacina teve um uso metafórico. Embora os estudos de ciência e mídia tenham se concentrado no jornalismo, Kirby (2014) defende a importância de analisar mídias de entretenimento para compreender a percepção pública da ciência. Mesmo dentro de mundos imaginados, que não podem ser submetidos a um regime verdadeiro/falso, as representações veiculadas por conteúdos ficcionais têm potencial

\footnotetext{
BUZZSUMO. Brighton, 2020. Disponível em: <https://bit.ly/3oFMkjz>. Acesso em: 17 mar. 2020.

2 A coleta foi realizada no dia 21 de maio de 2019. O BuzzSumo em sua versão gratuita de teste, utilizada nesta pesquisa, permite reunir as publicações de maior engajamento no período exato de um ano anterior ao dia da coleta. Por isso, o intervalo de tempo analisado compreende as datas de 22 de maio de 2018 a 21 de maio de 2019.

3 WAYBACK MACHINE. San Francisco, 2020. Disponível em: <https://bit.ly/38zDic3>. Acesso em: 17 mar. 2020.
} 
significativo para promover atitudes e visões positivas e negativas sobre a $C \& T$, questão importante para ser analisada em relação à vacinação.

Uma adaptação do método a conteúdos não jornalísticos já havia sido feita por Reznik, Massarani e Moreira (2019) em uma análise da representação da ciência e dos cientistas em curtas-metragens de animação, o que demonstra o potencial do método para avaliar diferentes formatos midiáticos. Sendo assim, adequamos o protocolo e suas categorias: “Características Gerais"; "Tema”, "Narrativa”, "Tratamento" e "Atores" às especificidades de nosso corpus: (1) os múltiplos formatos de conteúdo; e (2) a vacina como tema central das publicações (Tabela 1). Assim, foi possível compreender quais são os enquadramentos priorizados nesses debates públicos nas redes sociais, os enunciadores, as fontes, as vozes e as formas de representação.

Tabela I - Seções e critérios do protocolo de análise de conteúdos sobre vacina, adaptados a partir da metodologia desenvolvida por Massarani e Ramalho (2012)

\section{Seção Critério}

\begin{tabular}{|c|c|}
\hline \multirow{4}{*}{ Características gerais } & Veículo de publicação \\
\hline & Assinatura e autoria \\
\hline & Gênero do texto \\
\hline & Caráter da informação \\
\hline \multirow{4}{*}{ Tema } & Tipo de vacina \\
\hline & Posicionamento \\
\hline & Área de conhecimento principal \\
\hline & Área de conhecimento secundária \\
\hline Narrativa & Principais enquadramentos \\
\hline \multirow{9}{*}{ Tratamento } & Recursos visuais e audiovisuais \\
\hline & Há imagem de cientistas? \\
\hline & Há esclarecimento de termos científicos? \\
\hline & Há controvérsias? \\
\hline & Menciona benefícios, promessas, danos e/ou riscos da ciência? \\
\hline & Faz recomendações ao público? \\
\hline & Contextualiza? \\
\hline & Apresenta a ciência como atividade coletiva? \\
\hline & Demonstra preocupação com a divulgação científica? \\
\hline \multirow{2}{*}{ Atores } & Fontes \\
\hline & Vozes \\
\hline
\end{tabular}




\section{Resultados e discussão}

Apresentamos e discutimos, em seguida, os resultados da aplicação do protocolo de análise de conteúdo aos links sobre vacina que geraram maior engajamento em redes sociais entre 22 de maio de 2018 e 21 de maio de 2019, divididos pelas cinco seções consideradas neste estudo.

\section{Características gerais}

Nessa categoria, avaliamos formatos, gêneros, modos de produção e veracidade. No que diz respeito aos gêneros textuais, 70\% enquadram-se em gêneros jornalísticos, como a notícia e a reportagem, o que confirma o jornalismo como uma das principais fontes para o debate público sobre as vacinas. Historicamente, o jornalismo se constituiu como importante mediador dos acontecimentos sociais (Kovach; Rosenstiel, 2004). De tal modo, mesmo diante da pluralização informativa nas redes, o jornalismo ainda conserva um importante papel de semantizar os fenômenos sociais a um público amplo, inclusive no campo da ciência e da saúde.
Quanto ao caráter da informação, 81,6\% dos conteúdos contêm informações consideradas verdadeiras, isto é, verificáveis com base em fontes reconhecidas nas áreas em questão, seja científica, social ou política. Além disso, $6,9 \%$ foram classificados como fact-checking, prática de verificação de informações para atestar a precisão dos discursos públicos, das mensagens compartilhadas na rede, de propagandas comerciais e políticas, e para desmentir informações distorcidas e falsas. Estas últimas representam 3,4\% e 5,7\% da amostra, respectivamente. No âmbito da pesquisa, compreendemos informações distorcidas como aquelas que trazem informações corretas, mas fora de contexto ou com manchetes que induzem a uma interpretação equivocada. Já informações falsas seriam os conteúdos enganosos, tais como as fake news "Adolescente virgem diz que ficou grávida após tomar vacina contra gripe" ou "Trump alerta: a vacina da gripe é a maior fraude na história da medicina”. Identificamos ainda dois conteúdos ficcionais $(2,3 \%)$, um esquete de humor e uma cena de novela (Gráfico 1).

\section{Gráfico I - Avaliação do caráter da informação contida nos conteúdos analisados}

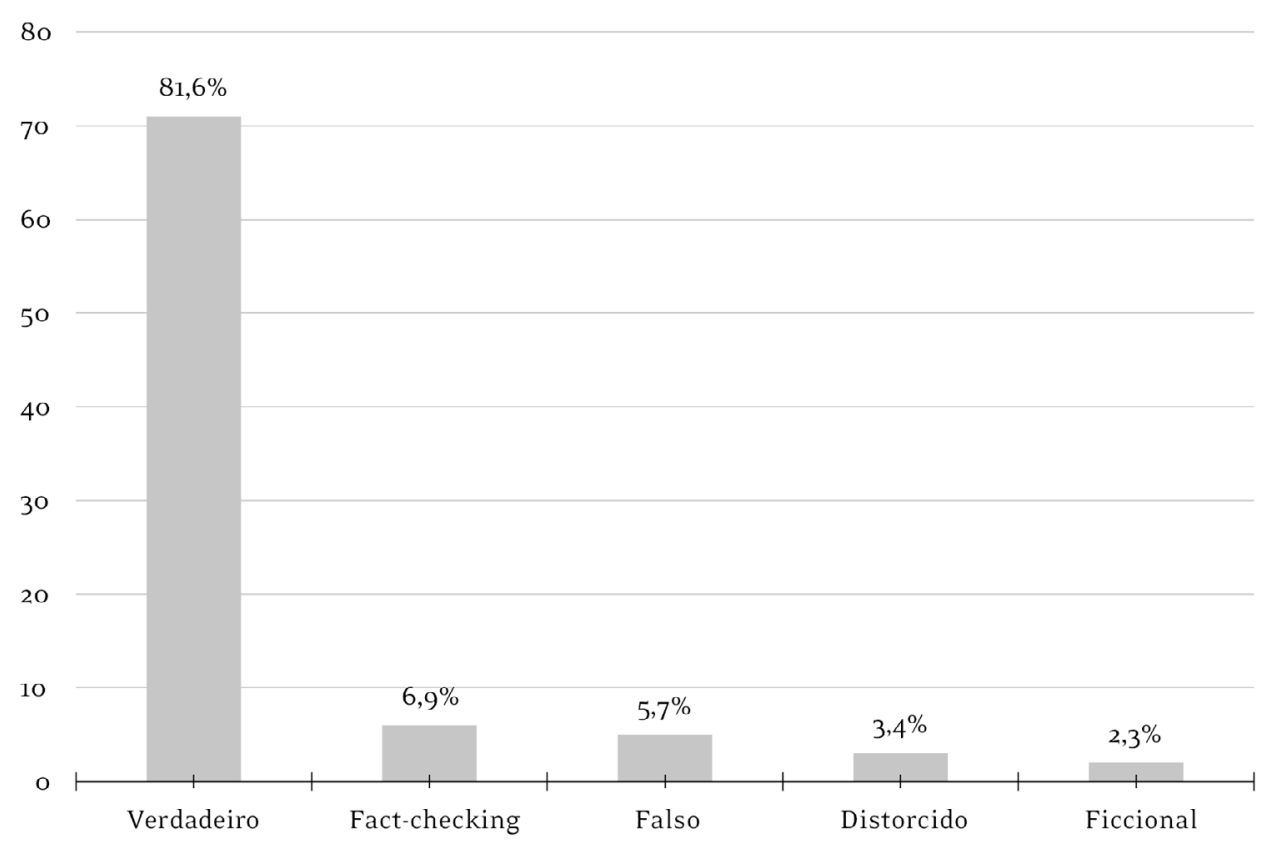


A presença de uma cena de novela entre os conteúdos de maior engajamento reforça que abordar assuntos científicos em telenovelas pode contribuir para pautar conversações sobre essas temáticas (Carvalho et al., 2016). Por sua vez, o esquete de humor critica o movimento antivacina, reafirmando a importância da vacinação. Portanto, o potencial de conteúdos ficcionais para divulgação científica não deve ser desprezado, já que com diferentes linguagens eles podem colaborar para fomentar a importância da ciência (Kirby, 2014).

Verificamos ainda a presença ou não de assinatura ou autoria dos textos como um importante elemento para atribuição de confiabilidade e responsabilização do conteúdo compartilhado. Do total de links, 41,4\% não trouxeram qualquer identificação de autoria. O percentual expressivo pode sugerir que nem sempre esse é um critério observado pelos usuários da rede para compartilhar conteúdos. Nesse percentual, estão inclusos os cinco conteúdos identificados como falsos ou incorretos. Além disso, quase metade $(49,4 \%)$ tem assinatura pessoal de um jornalista ou produtor de conteúdo; 4,6\% têm assinatura institucional de uma agência de notícias; e 4,6\% são assinados por um jornalista e uma agência de notícias (Gráfico 2).

\section{Gráfico 2 - Tipo de assinatura dos conteúdos analisados}

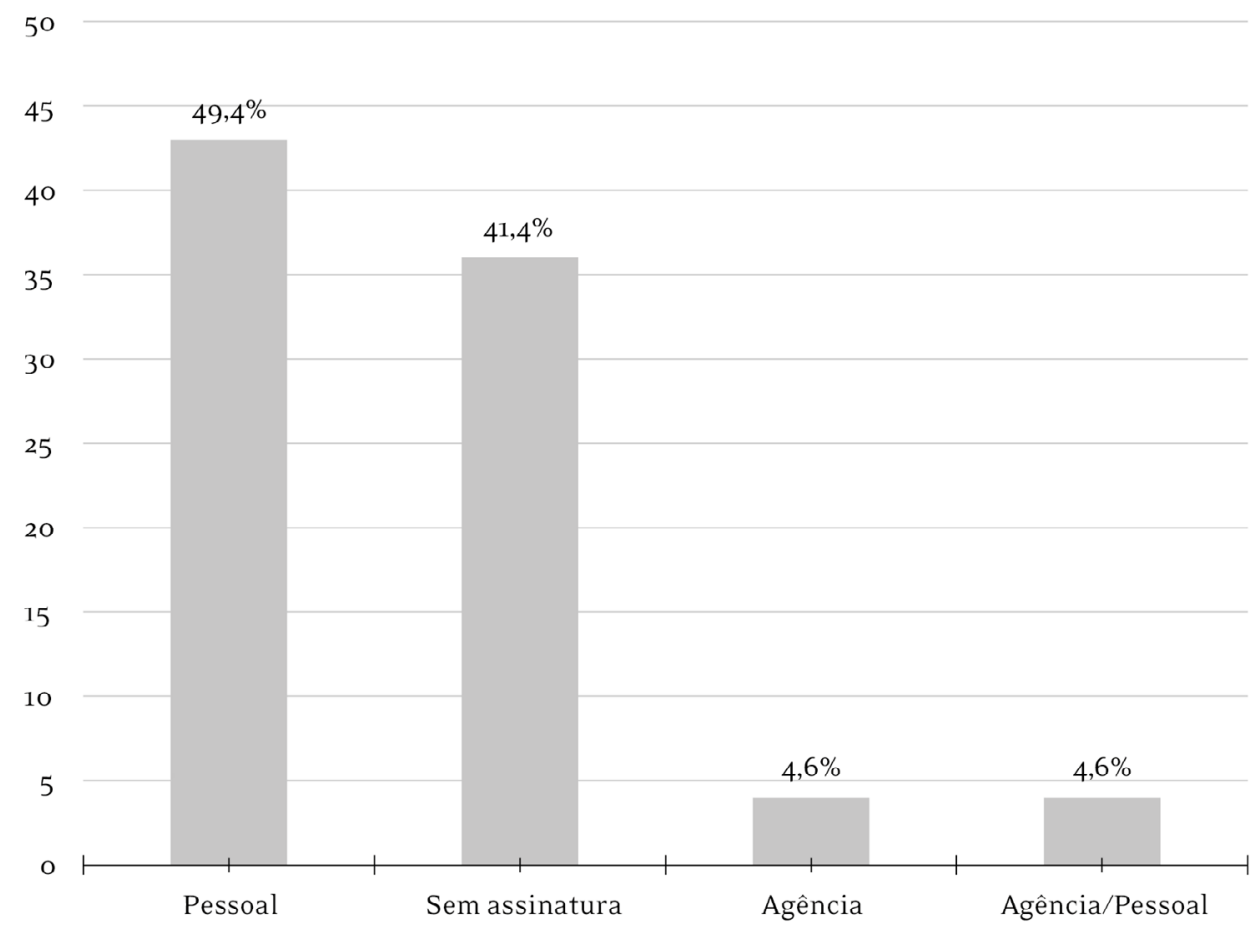

\section{Tema}

Nessa seção, analisamos as abordagens e as temáticas mais comuns aos textos que geraram maior engajamento nas redes sociais. Entre os tipos de vacinas, há uma proeminência das “vacinas preventivas" $(66,7 \%)$, empregadas para prevenção de doenças como sarampo e poliomielite. Contudo, há também a presença marcante das "vacinas terapêuticas" (24,1\%). Diferentemente das vacinas preventivas, as terapêuticas têm o objetivo de controlar infecções e doenças já instaladas no indivíduo a ser tratado (Diniz; Ferreira, 2010), estimulando a resposta imunológica do organismo para casos que vão desde rinites alérgicas até HIV (Gráfico 3). 
Gráfico 3-Tipo de vacina mencionada nos conteúdos analisados

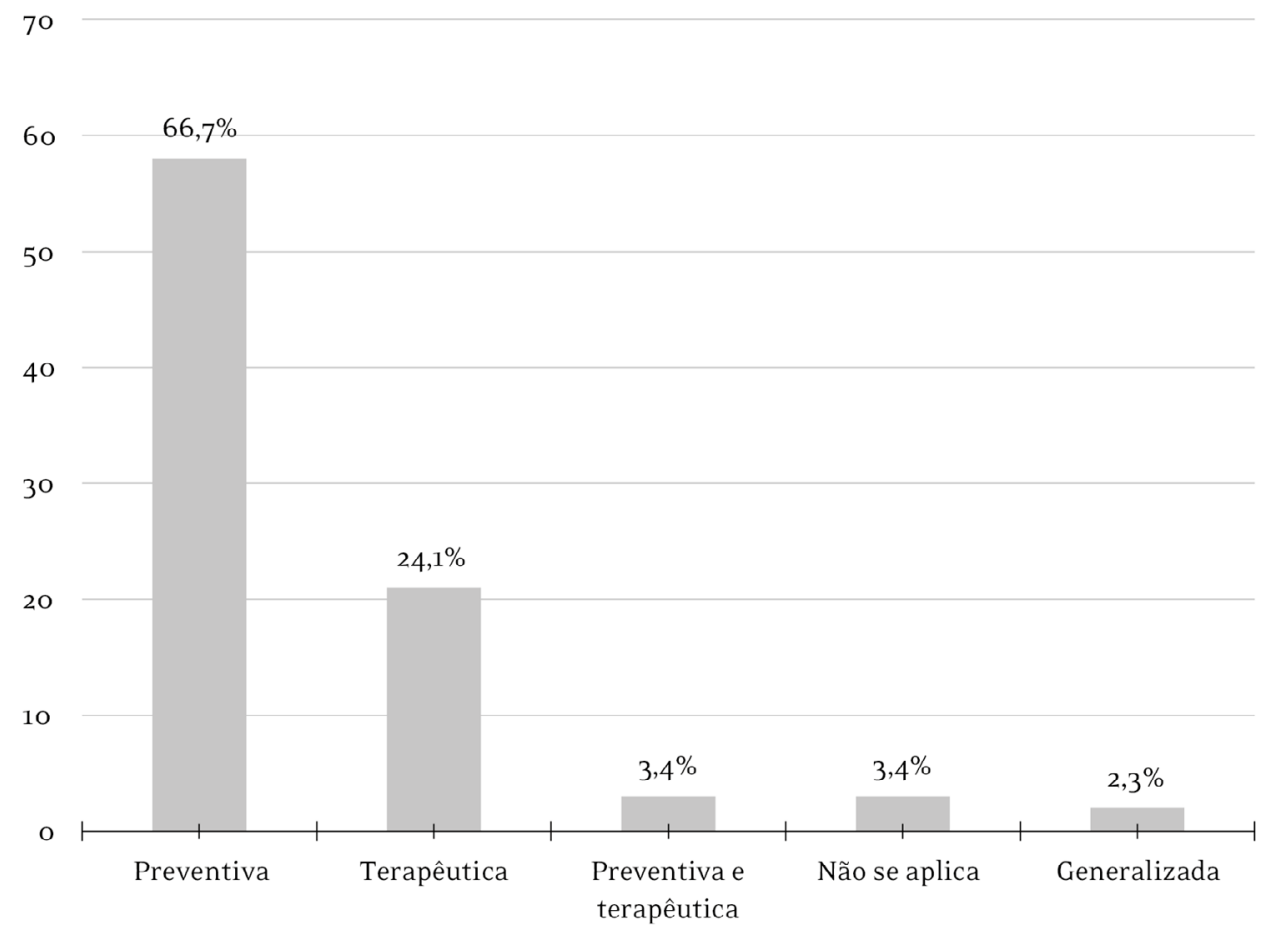

A categoria "não se aplica” compreende os textos em que a vacina não foi usada no sentido técnico, e sim metafórico. De acordo com a classificação de Kinouchi, Kinouchi e Mandrá (2012), trata-se de uma metáfora cientificamente inspirada, ou a transformação de um termo científico em uma expressão do senso comum, que passa a ser utilizada em sentido abstrato em outros contextos. Para os autores, investigar como conceitos de C\&T são apropriados pela linguagem comum permite entender a cultura científica de uma época. Assim, avaliar os sentidos metafóricos que essas palavras ganham tanto traz pistas sobre o entendimento das pessoas sobre aquele tema quanto reconhece o papel da divulgação científica em ir além da transmissão literal de conteúdos de C\&T, contribuindo para enriquecer o repertório conceitual da população e para ampliar suas possibilidades de descrever e conhecer o mundo e seus processos.
O uso metafórico da palavra "vacina” $(3,4 \%)$ tem o sentido de "solução", “antídoto", "prevenção” ou "proteção", o que indica algum grau de conhecimento sobre as funções dessa tecnologia. Além disso, percebemos um sentido positivo nesse uso metafórico, isso demonstra a disseminação de um imaginário em que se reconhece que as vacinas funcionam, previnem, protegem e solucionam problemas.

Observamos ainda quais são os principais posicionamentos em relação às vacinas. Há um forte engajamento em torno de conteúdos próvacina $(87,4 \%)$, seguidos pelos neutros $(6,9 \%)$, com argumentos contra e a favor $(3,4 \%)$ e contrários à vacinação (2,3\%). Ainda que esses números apontem a um menor percentual de engajamento de discursos antivacina, são necessários mais estudos para verificar seus impactos em grupos fechados em redes sociais e aplicativos de mensagens. 
Gráfico 4 - Análise dos posicionamentos sobre a vacina nos conteúdos analisados

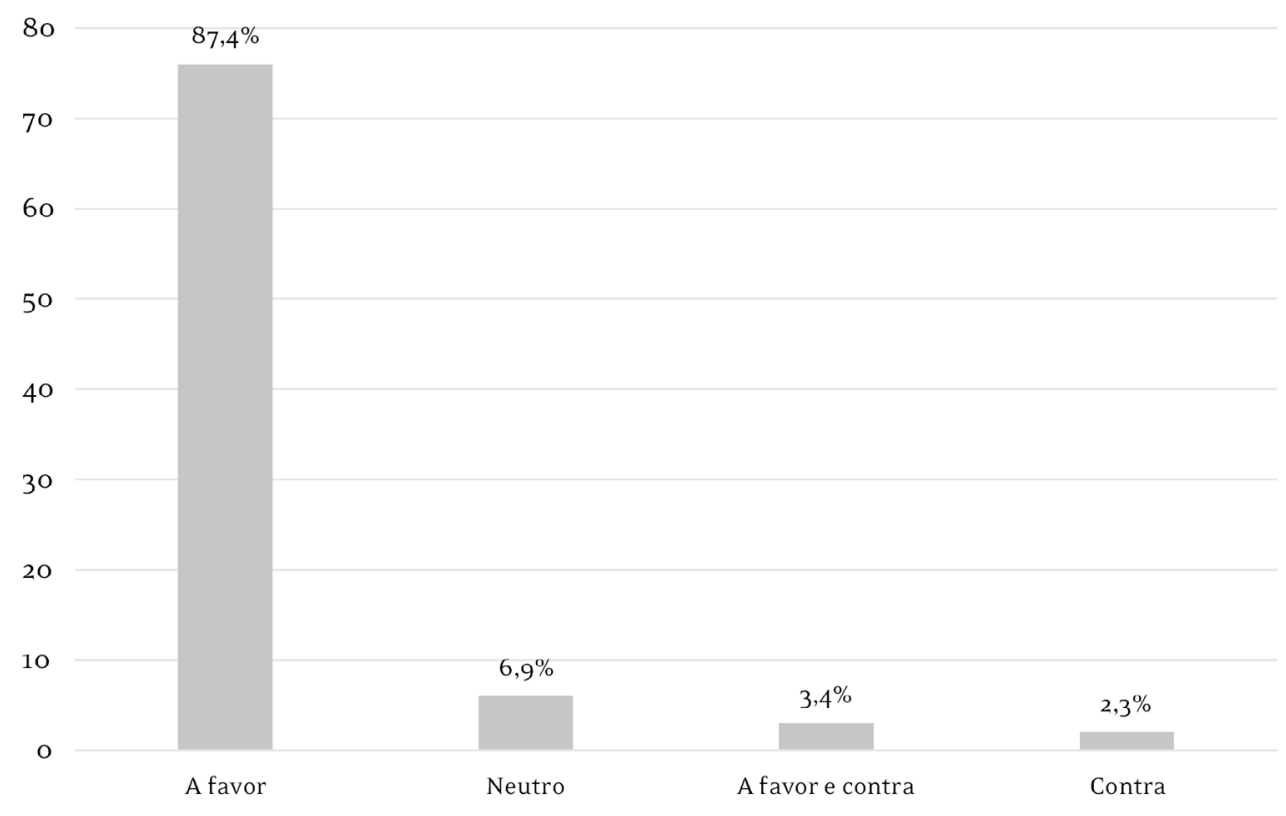

Já as áreas do conhecimento articuladas por esse corpus nos permitem enxergar quais são os principais vieses e temáticas que mais despertaram o debate público. A divisão das áreas do conhecimento é um objeto de preocupação dentro da ciência da informação, com vista a gerar instrumentos de apoio à organização e sistematização de dados em C\&T (Souza, 2004). Em um debate transversal como o da vacina, é essencial compreender quais são as áreas privilegiadas nas redes. Optamos por determinar uma área principal e possíveis áreas de conhecimento secundárias (Tabela 2).

Tabela 2 - Distribuição dos conteúdos a partir das áreas de conhecimento abordadas

\begin{tabular}{|c|c|c|}
\hline Área de Conhecimento & Aparições como "Principal" & $\begin{array}{l}\text { Aparições como } \\
\text { "Secundária" }\end{array}$ \\
\hline Medicina e saúde & 49 & 25 \\
\hline Sociais e humanas & 37 & 14 \\
\hline Ciência e tecnologia, como um todo & 1 & 0 \\
\hline Biológicas & 0 & 10 \\
\hline Engenharias e tecnologias & 0 & 2 \\
\hline
\end{tabular}


A soma das "áreas secundárias" é menor que o total de links, já que alguns conteúdos não trataram de mais de um segmento, enquanto outros traziam uma ou até duas áreas secundárias. O campo da medicina e saúde aparece como hegemônico, seguido pelas ciências sociais e humanas, devido à ênfase em políticas públicas e análises sociais.

\section{Narrativa}

A dimensão da narrativa é baseada no conceito de enquadramento (framing), que entende um quadro (frame) como a ideia central que sintetiza a linha argumentativa adotada em determinado texto, contribuindo para a produção de sentido a respeito do assunto em questão (Massarani; Ramalho, 2012). O modo como as vacinas são enquadradas por discursos midiáticos pode influenciar a percepção e, consequentemente, o comportamento das pessoas sobre a imunização (Pența; Băban, 2018). Estabelecemos 12 frames para o tema "vacina", que foram incorporados ao protocolo, ordenados na Tabela 3 dos mais para os menos predominantes no material analisado. Um único conteúdo pode mobilizar um ou mais enquadramentos, o que foi considerado na análise.

\section{Tabela 3 - Descrição dos enquadramentos analisados nos conteúdos e distribuição dos resultados por percentual encontrado}

Enquadramento Descrição

Políticas públicas

Impacto da CET

Novo desenvolvimento tecnológico

Personalização

Social, ambiental e cultural

Antecedentes/Background científico

Econômico e mercadológico

Incertezas científicas

Nova pesquisa
Foca em ações, programas e estratégias governamentais sobre desenvolvimento, produção, distribuição, campanhas e cobertura vacinal; os serviços de saúde disponibilizados no Sistema Único de Saúde; e os debates sobre vacina que integram a pauta política proposta por partidos políticos, $44,8 \%$ movimentos sociais e outras organizações da sociedade civil. Trata ainda da desconfiança e da descrença em relação ao serviço público.

Trata do impacto que o desenvolvimento científico e tecnológico pode gerar na sociedade e na qualidade de vida de indivíduos e da coletividade.

Presença no corpus

Anuncia aplicação de descobertas, de novas vacinas, de novos resultados experimentais e de ensaios clínicos.

$31,0 \%$

Destaca histórias pessoais que envolvam a vacina abordada.

Aborda aspectos religiosos, culturais e sociais, reflexões sobre filosofias alternativas de vida e a relação com o meio ambiente.

Apresenta antecedentes científicos gerais sobre as vacinas, como pesquisas anteriores, recapitulação dos resultados e $12,6 \%$ conclusões já conhecidas.

Enfatiza ações empresariais no setor de biotecnologia, preços, investimentos, patentes, oportunidades e

$12,6 \%$ competitividade nacional no mercado globalizado.

Trata de riscos à saúde, efeitos adversos e limites da ciência na produção de conhecimento e na gestão de riscos presentes e futuros.

$11,5 \%$

Discute as bases científicas e médicas das novas pesquisas e as descobertas sobre vacina.
$5,7 \%$ 
Tabela 3-Continuação
Enquadramento
Descrição
Presença no
corpus
Bioético e/ou jurídico
Expressa os princípios legais, éticos e morais, como
a aceitabilidade de riscos presumidos e a obrigatoriedade
$3,4 \%$
da vacina ante a liberdades individuais.
Controvérsias científicas
Foca nas controvérsias científicas relacionadas à vacina
e vacinação.
$1,1 \%$
Trata de catástrofes produzidas pela vacina; da impossibilidade
Caixa de Pandora
de controle absoluto sobre ela, dando como certo o seu
$0,0 \%$
retorno negativo.

O enquadramento predominante é o de "políticas públicas", presente em quase metade dos textos analisados. Assim, percebe-se que há um forte engajamento em torno da ação dos entes públicos. Outro enquadramento com grande apelo é o dos impactos da C\&T, que salienta os desdobramentos do avanço científico para indivíduos e sociedade. O desenvolvimento tecnológico de novas vacinas ou novas aplicações também teve relevância no período. Por outro lado, nenhum dos textos avaliados traz o enquadramento "caixa de Pandora”, uma abordagem catastrofista que assume como certo o retorno negativo das vacinas na saúde pública.

\section{Tratamento}

Nessa categoria, avaliamos a presença de recursos multimídia; explicação de algum termo científico; contextualização do assunto; menção a alguma controvérsia (científica ou não); recomendação ao público; apresentação da ciência como atividade coletiva; preocupação com divulgação científica; e menção a consequências da ciência (benefícios, promessas, danos e/ou riscos). Essa seção se baseia no entendimento de que a presença desses elementos indica maior preocupação do veículo com a qualidade da informação científica. Algumas dessas categorias revelam indícios que podem conduzir a futuros estudos em profundidade.

Em relação aos recursos midiáticos, encontramos predominantemente fotografias $(82,8 \%)$, seguidas por vídeos ( $8 \%$ ) e áudios (4,6\%). As imagens mais comuns são seringas, agentes de saúde e crianças chorando durante a aplicação. Apenas quatro links trazem imagem de um cientista.

Somente $24,1 \%$ dos conteúdos analisados explicam um termo científico e $23 \%$ abordam algum tipo de controvérsia. Já 9,2\% tratam de controvérsias inerentes ao campo científico, tais como o desequilíbrio de gênero entre os voluntários de um estudo; a falta de consenso sobre determinadas aplicações e tratamentos; e o debate sobre o risco de que as vacinas poderiam levar ao autismo.

A já discutida ampla maioria de posicionamentos pró-vacina é corroborada por uma visão otimista, uma vez que mais da metade dos conteúdos dão ênfase aos benefícios (vantagens atuais) trazidos pelas vacinas. Há também uma significativa presença de promessas (vantagens potenciais), enquanto danos e riscos são menos abordados (desvantagens atuais e potenciais, respectivamente) (Gráfico 5). 


\section{Gráfico 5 - Tratamento dos conteúdos analisados em relação às possíveis consequências da vacinação}

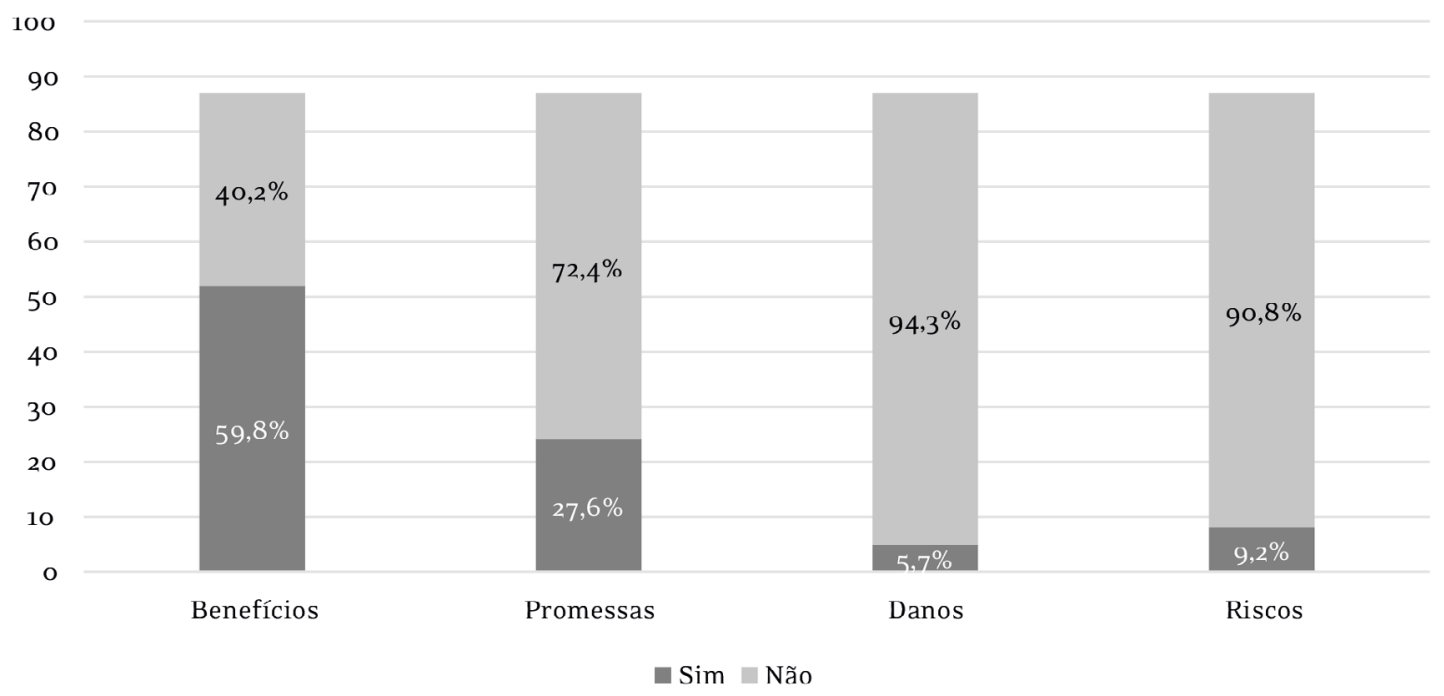

A maioria dos conteúdos contextualiza os acontecimentos $(73,6 \%)$, mas apenas pouco mais de um terço (39,1\%) fazem algum tipo de recomendação de saúde. Também são poucas as matérias que apresentam a ciência enquanto atividade coletiva (29\%), reforçando o imaginário do cientista sozinho no laboratório. Nesse mesmo sentido, somente $23 \%$ dos conteúdos promovem divulgação científica, por exemplo, detalhando o passo a passo da pesquisa científica, apresentando artigos, ou expondo resultados parciais de investigações em andamento.

Uma vez que diferentes níveis de incerteza podem levar à hesitação vacinal (Kennedy, 2020; OMS, 2014), esses resultados indicam uma tendência preocupante acerca da qualidade dos conteúdos analisados em relação ao esclarecimento de possíveis dúvidas sobre as vacinas. 0 menor percentual de textos que explicam termos científicos e abordam controvérsias indica que esses conteúdos podem partir de uma visão de que esses conhecimentos já estão sedimentados na população, o que as pesquisas sobre hesitação vacinal demonstram não ser um consenso. Ao terem dúvidas sobre as vacinas, que não são esclarecidas nos conteúdos que buscam nas redes sociais, indivíduos podem estar mais expostos a conteúdos desinformativos que se sustentam em argumentos aparentemente convincentes.
Atores

A última dimensão trabalhada neste estudo explora os atores que contribuem para a construção da narrativa. Compreendemos as fontes como os dados e informações consultadas para construção do texto, e as vozes como os indivíduos a quem é concedida a possibilidade de falar. Nesse recorte analítico, portanto, vozes também são enquadradas como fontes. Por meio desses dados, podemos avaliar qual tipo de autoridade fundamenta os discursos a respeito da questão da vacina e se há contrastes significativos na relação entre fontes e vozes. Codificamos os atores a partir da maneira como eles são apresentados nos conteúdos.

No jornalismo, as fontes são portadoras de uma informação, podendo ser pessoais, institucionais, documentais, oficiais ou independentes (Lage, 2001). Sendo assim, algumas fontes são reconhecidas e autorizadas para falar em processos de inter-relação e disputas com a comunidade dos jornalistas (Wolf, 1999). Portanto, analisar as fontes e as vozes sobre as vacinas demonstra quais indivíduos e instituições são privilegiados em pautar esses debates.

Em relação às fontes, há uma preponderância de instituições governamentais e seus representantes, 
mencionadas em $51,7 \%$ dos conteúdos; seguidas por outros veículos jornalísticos (39,1\%); cientistas, universidades e instituições de pesquisa (34,5\%); médicos (26,4\%); e publicações científicas (20,7\%) (Gráfico 6).

Entre as vozes, há ainda um predomínio de fala concedida às autoridades públicas, ouvidas em 29,9\% dos conteúdos; seguidas por cientistas (27,6\%) e médicos (25,3\%) (Gráfico 7). A análise das fontes e vozes aponta a um privilégio de agentes públicos frente aos membros do campo científico, o que sugere que o debate público nas redes prioriza os enquadramentos políticos, como campanhas governamentais e políticas públicas.

\section{Gráfico 6 - Distribuição das fontes citadas nos conteúdos analisados}

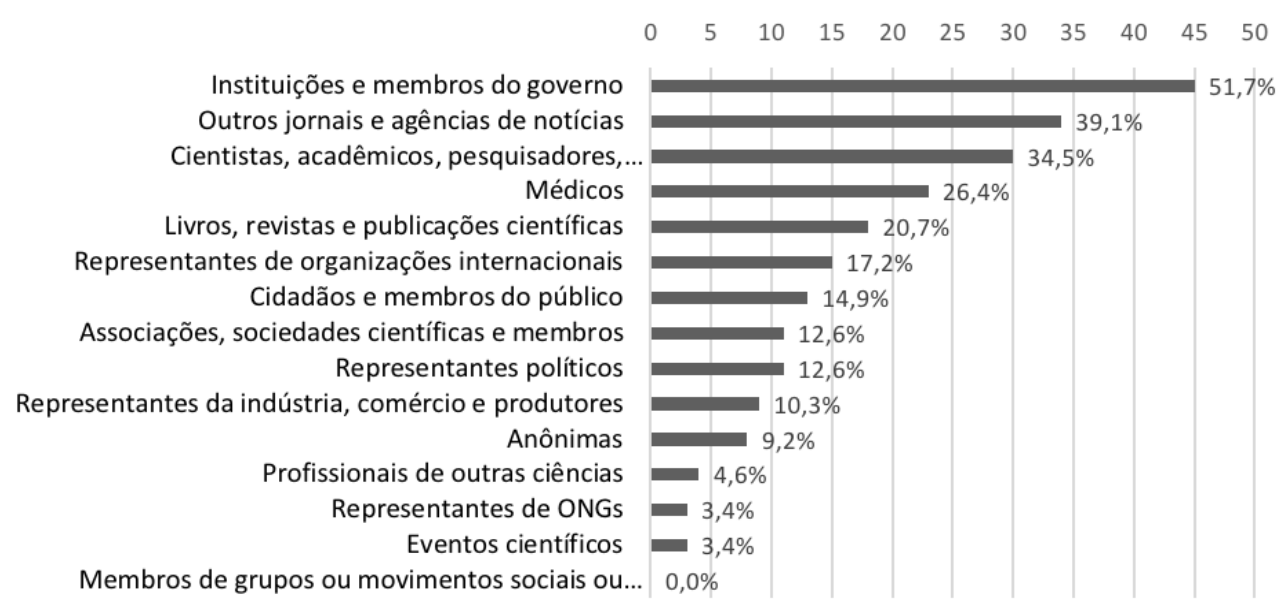

\section{Gráfico 7 - Distribuição das vozes entrevistadas nos conteúdos analisados}

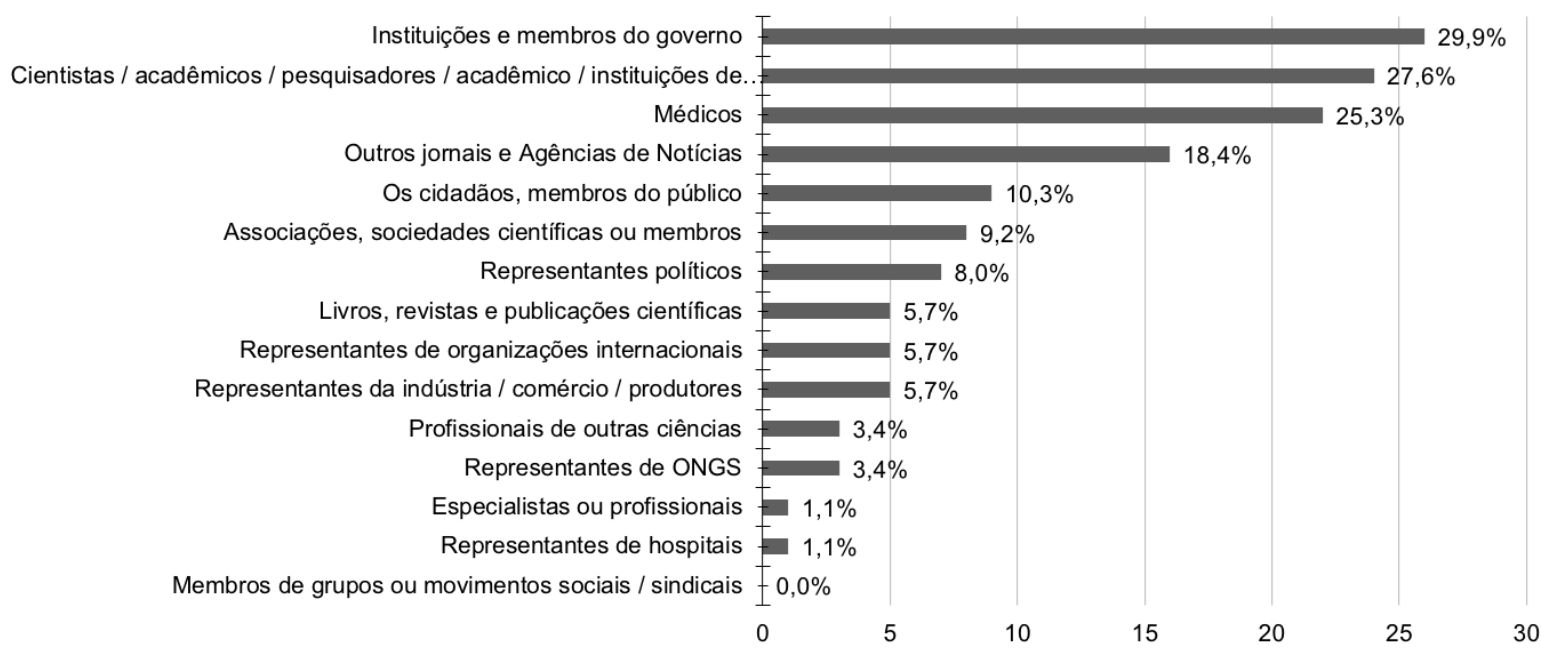

Contudo, é preciso ressaltar que cinco $(5,7 \%)$ dos links mais compartilhados foram identificados como falsos, e três $(3,4 \%)$ como distorcidos. Assim, podemos considerar que as fontes e vozes atribuídas nesses discursos possam estar descontextualizadas, deturpadas ou serem efetivamente falsas. Desse total de oito links, seis fazem referências a instituições ou membros do governo de modo genérico ("autoridades de saúde mexicanas”) ou nominal (“Anvisa”, “DOU”). Outros três indicam supostos pesquisadores e médicos como fontes ("estudante de doutorado Alexa Goldberg”; “Dr. Hersch”). Esse recurso também foi 
encontrado por Costa et al. (2020) em vídeos favoráveis ao movimento antivacina no YouTube, em que supostos médicos, cuja autoridade é reforçada por aspectos imagéticos como vestimentas associadas à profissão, legitimam a hesitação vacinal.

É possível inferir que a autoridade de organizações governamentais e de profissionais da ciência e saúde é emulada por esses discursos com o intuito de construir uma aura de confiabilidade e convencimento. A fonte falsa apresentada como “Alexa Goldberg" estaria realizando doutorado em "gravidez vacinal”. O próprio risco inexistente da vacina que é mote da fake news é descrito como um tema de pesquisa científica. Sendo assim, vemos que a desinformação consiste em um fenômeno cuja complexidade vai além da descredibilização da ciência. Em teorias da conspiração que circulam nas redes sociais, pesquisas científicas são frequentemente acionadas para deslegitimar a própria ciência (Oliveira, 2020). Esse processo de desinformação aponta para um cenário perigoso em que autoridades da saúde pública, cientistas e médicos podem ser instrumentalizados como fontes e vozes válidas apenas quando confirmam sistemas de crença prévios. Desse modo, esses atores podem ser usados como instrumentos retóricos para fins ideológicos, ao mesmo tempo em que a ciência é deslegitimada como campo de saber quando vai de encontro a visões particulares.

\section{Considerações finais}

A análise de conteúdo realizada nas publicações sobre vacina que alcançaram mais engajamento em redes sociais entre 2018 e 2019 revelou apontamentos importantes para compreender o consumo de informações sobre vacinas nesses espaços. Em relação às características gerais, a maioria dos conteúdos é jornalística (70\%), tem informações verdadeiras (81,6\%) e apresenta indicação de autoria pessoal (49,4\%). No âmbito dos temas, destaca-se um posicionamento pró-vacina $(87,4 \%)$, bem como uma ênfase nos benefícios das vacinas (59,8\%) no que diz respeito ao tratamento dos conteúdos. Esses resultados, analisados em conjunto, apontam a uma circulação de narrativas majoritariamente positivas sobre a vacinação.
Ainda na esfera dos temas, predominam as vacinas preventivas $(66,7 \%)$, seguidas pelas terapêuticas $(24,1 \%)$, em abordagens vinculadas a questões da área de medicina e saúde. Frequentemente, os textos trataram de duas ou mais áreas de conhecimento, o que indica um reconhecimento da vacinação como um tema complexo, atravessado por diversas interfaces científicas e sociais. A ocorrência da área de ciências sociais e humanas na segunda posição, em confluência com a relevância do enquadramento de políticas públicas $(44,8 \%)$, sugere um reconhecimento da vacinação como uma questão de saúde pública. Esse quadro se repete na análise dos atores, em que os agentes públicos representam as fontes citadas em mais da metade dos conteúdos $(51,7 \%)$ e são as principais vozes ouvidas (29,9\%). É necessário, assim, conduzir outras pesquisas sobre as narrativas em torno da vacinação e de seus agentes públicos, uma vez que muitas vezes a insegurança não é atribuída às vacinas em si, mas à pretensa parcialidade ou irresponsabilidade das autoridades que conduzem o processo de vacinação (Massarani; Leal; Waltz, 2020).

Em um contexto em que a hesitação vacinal e a desinformação ameaçam a saúde pública, não se pode desconsiderar a ocorrência de conteúdos falsos (5,7\%) e distorcidos $(3,4 \%)$, e de posicionamentos neutro $(6,9 \%)$ e contrário $(2,3 \%)$ à vacinação entre os links com mais engajamento nas redes sociais. Além disso, a presença de $41,4 \%$ de conteúdos sem qualquer identificação de autoria entre eles, a totalidade dos classificados como falsos - aponta para práticas de consumo em mídias sociais que podem favorecer o espalhamento de informações que não passam por um procedimento de checagem ou responsabilização.

Outros dados mostram lacunas no tratamento dos conteúdos analisados. É minoritária a ocorrência de conteúdos que esclarecem um termo científico (24,1\%), que tratam a ciência como atividade coletiva (29\%) e que fazem recomendações de saúde $(39,1 \%)$. Diante desses dados, questiona-se se esses conteúdos têm colaborado para sanar possíveis dúvidas dos interagentes em relação às vacinas, bem como para esclarecer de que forma a vacinação deve ser inserida no cotidiano. Ainda nesse aspecto, apenas $23 \%$ dos 
conteúdos abordam algum tipo de controvérsia quanto à vacinação, e a discussão sobre controvérsias científicas é de 9,2\%. Para garantir o entendimento da segurança e da eficácia das vacinas por toda a população, é necessário que possíveis controvérsias em torno dessa temática encontrem espaços para debates e esclarecimentos.

Por fim, o jornalismo, cujo formato é majoritário entre os conteúdos analisados (70\%), reforça sua importância como campo capaz de pautar o debate público sobre questões de C\&T, entre elas, a da vacinação. Quando a hesitação vacinal coloca em risco populações inteiras, é fundamental que o combate à desinformação sobre vacinas seja entendido como uma questão de saúde pública. Nesse sentido, é importante que um conjunto de atores sociais, entre cientistas, agentes públicos, profissionais de saúde, de mídia e do jornalismo, promovam o acesso a conteúdos de qualidade sobre a vacinação em redes sociais. Portanto, a contínua aproximação entre a divulgação científica e o jornalismo, com o intercâmbio de saberes acadêmicos e práticos dos dois campos, pode contribuir para suscitar nas redes sociais um debate público de qualidade e confiabilidade acerca da vacinação.

\section{Referências}

AVAAZ; SBIm - SOCIEDADE BRASILEIRA DE IMUNIZAÇÕES. As fake news estão nos deixando doentes? São Paulo: Avaaz, nov. 2019. Disponível em: <https://bit.ly/3bAYwIs>. Acesso em: 27 abr. 2020.

BAKIR, V.; MCSTAY, A. Fake news and the economy of emotions: problems, causes, solutions. Digital Journalism, London, v. 6, n. 2, p. 154-175, 2017.

CANCIAN, N. Pela primeira vez no século, Brasil não atinge meta para nenhuma das principais vacinas infantis. Folha de São Paulo, São Paulo, 7 set. 2020. Notícias. Disponível em: 〈https://bit.ly/3rNGLeY>. Acesso em: 8 set. 2020.

CARVALHO, V. B. et al. A ciência e a tecnologia na TV brasileira: uma análise da programação da TV Globo. Galáxia, São Paulo, n. 33, p. 184-198, 2016.
COSTA, B. B. et al. O movimento antivacina no YouTube nos tempos de pós-verdade: educação em saúde ou desinformação? Mídia e Cotidiano, Rio de Janeiro, v. 14, n. 1, p. 220-239, 2020.

CUESTA-CAMBRA, U.; MARTÍNEZ-MARTÍNEZ, L.; NIÑO-GONZÁLEZ, J. I. An analysis of pro-vaccine and anti-vaccine information on social networks and the internet: visual and emotional patterns. El Profesional de la Información, Barcelona, v. 28. n. 2, art. e280217, 2019.

DINIZ, M. O.; FERREIRA, L. C. S. Biotecnologia aplicada ao desenvolvimento de vacinas. Estudos Avançados, São Paulo, v. 24, n. 70, p. 19-30, 2010.

ECDC - EUROPEAN CENTRE FOR DISEASE PREVENTION AND CONTROL. Seasonal influenza vaccination in Europe: vaccination recommendations and coverage rates in the EU Member States for eight influenza seasons 20072008 to 2014-2015. Solna, 2017. Disponível em: <https://bit.ly/3rFE7I2>. Acesso em: 7 set. 2020.

GADELHA, C. A. G. et al. Acesso a vacinas no Brasil no contexto da dinâmica global do Complexo Econômico-Industrial da Saúde. Cadernos de Saúde Pública, Rio de Janeiro, v. 36, art. eoo154519, 2020. Suplemento 2.

KENNEDY, J. Vaccine hesitancy: a growing concern. Pediatric Drugs, Cham, v. 22, n. 2, p. 105-111, 2020.

KINOUCHI, O.; KINOUCHI, J. M.; MANDRÁ, A. A. Metáforas científicas no discurso jornalístico. Revista Brasileira de Ensino de Física, São Paulo, v. 34, n. 4, art. 4402, 2012.

KIRBY, D. Science and technology in film: themes and representations. In: BUCCHI, M.; TRENCH, B. (Org.). Routledge handbook of public communication of science and technology. London: Routledge, 2014. p. 97-112.

KOVACH, B.; ROSENSTIEL, T. Os elementos do jornalismo: o que os jornalistas devem saber $\mathrm{e}$ o público exigir. São Paulo: Geração Editorial, 2004.

KRISHNA, A. Poison or prevention? Understanding the linkages between vaccinenegative individuals' knowledge deficiency, motivations, and active communication behaviors. Health Communication, London, v. 33, n. 9, p. 1088-1096, 2018. 
LAGE, N. A reportagem: teoria e técnica de entrevista e pesquisa jornalística. Rio de Janeiro: Record, 2001.

MASSARANI, L.; LEAL, T.; WALTZ, I. O debate sobre vacina em redes sociais: uma análise exploratória dos links com maior engajamento. Cadernos de Saúde Pública, Rio de Janeiro, v. 36, art. eoo148319, 2020. Suplemento 2.

MASSARANI, L.; RAMALHO, M. (Org.). Monitoramento e capacitação em jornalismo científico: a experiência de uma rede iberoamericana. Rio de Janeiro: Museu da Vida, 2012. MOLINA-CAÑABATE, J. P.; MAGALLÓN-ROSA, R. Desinformación y periodismo científico: el caso de Maldita Ciencia. Revista Mediterránea de Comunicación, Alicante, v. 11, n. 2, p. 11-21, 2020.

MOORHEAD, S. A. et al. A new dimension of health care: systematic review of the uses, benefits, and limitations of social media for health communication. Journal of Medical Internet Research, Toronto, v. 15, n. 4, art. e85, 2013.

OLIVEIRA, T. Desinformação científica em tempos de crise epistêmica: circulação de teorias da conspiração nas plataformas de mídias sociais. Fronteiras: Estudos Midiáticos, São Leopoldo, v. 22, n. 1, p. 21-35, 2020.

OMS - ORGANIZAÇÃO MUNDIAL DA SAÚDE. Report of the Sage working group on vaccine hesitancy. Geneva, 2014. Disponível em: <https://bit.ly/3ljqnAt>. Acesso em: 16 set. 2020.

PENȚA, M. A.; BĂBAN, A. Message framing in vaccine communication: a systematic review of published literature. Health Communication, London, v. 33, n. 3, p. 299-314, 2018.

REZNIK, G.; MASSARANI, L.; MOREIRA, I. C. Como a imagem de cientista aparece em curtas de animação? História, Ciências, Saúde-Manguinhos, Rio de Janeiro, v. 26, n. 3, p. 753-777, 2019.

SCHEUFELE, D. A.; KRAUSE, N. M. Science audiences, misinformation, and fake news. PNAS, Washington, DC, v. 116, n. 16, p. 7662-7669, 2019.

SILVA JUNIOR, J. B. 40 anos do Programa Nacional de Imunizações: uma conquista da saúde pública brasileira. Epidemiologia e Serviços de Saúde, Brasília, DF, v. 22, n. 1, p. 7-8, 2013.
SOUZA, R. F. Áreas do conhecimento. DataGramaZero, Rio de Janeiro, v. 5, n. 2, art. Ao2, 2004.

TADDICKEN, M.; WOLFF, L. "Fake news" in science communication: emotions and strategies of coping with dissonance online. Media and Communication, Lisboa, v. 8, n. 1, p. 206-217, 2020.

TANDOC JUNIOR, E. C.; LIM, Z. W.; LING, R. Defining "fake news": a typology of scholarly definitions. Digital Journalism, London, v. 6, n. 2, p. 137-153, 2017.

TEMPORÃO, J. G. O Programa Nacional de Imunizações (PNI): origens e desenvolvimento. História, Ciências, Saúde-Manguinhos, Rio de Janeiro, v. 10, p. 601-617, 2003. Suplemento 2.

VASCONCELLOS-SILVA, P. R.; CASTIEL, L. D.; GRIEP, R. H. A sociedade de risco midiatizada, o movimento antivacinação e o risco do autismo. Ciência \& Saúde Coletiva, Rio de Janeiro, v. 20, n. 2, p. 607-616, 2015.

WARDLE, C.; DERAKHSHAN, H. Information disorder: toward an interdisciplinary framework for research and policy making. Strasbourg: Council of Europe, 2017. Disponível em: <https://bit.ly/3vfB6Aj>. Acesso em: 27 abr. 2020.

WELLCOME. Wellcome global monitor: how does the world feel about science and health? London, 2019. Disponível em: <https://bit.ly/2ONPAq8>. Acesso em: 27 abr. 2020.

WOLF, M. Teorias da comunicação. Lisboa: Presença, 1999.

\section{Contribuição dos autores}

Massarani concebeu o estudo, definiu o desenho metodológico e orientou todas as etapas do trabalho. Waltz e Leal desenvolveram a discussão teórica, analisaram os dados e redigiram o artigo. Modesto aplicou o protocolo nos dados e participou da análise.

Recebido: $23 / 09 / 2020$

Aprovado: 03/12/2020 